\title{
The production of hydrogen as an alternative energy carrier from aluminium waste
}

\author{
Esam Elsarrag* ${ }^{*}$, Ammar Elhoweris and Yousef Alhorr
}

\begin{abstract}
Background: Aluminium dross is a valuable resource that is often redirected to landfill as there are no real viable solutions for the utilisation of this industrial waste. A study has been conducted to provide a recycling process where the dross is reacted with an alkaline solution in order to generate hydrogen with bayerite and gibbsite products.
\end{abstract}

Methods: Samples of aluminium dross were obtained from two sources: aluminium dross obtained from an aluminium recycling facility, recycled dross (RD) in Qatar and aluminous dross samples which were to be directed to landfill, landfill dross (LD), also in Qatar. Quantities of each sample were weighed in amounts that would contain equal amounts of aluminium reacting with an aqueous $\mathrm{NaOH}$ solution to generate hydrogen. The generated hydrogen has been analysed and compared with that reported in the literature.

Results: Certainly, the lower purity sample LD was treated at a lower standard than the recycled dross. The LD and $\mathrm{RD}$ samples generated 0.15 and $0.5 \mathrm{~g} / \mathrm{l} \mathrm{Al}$, respectively, with the landfilled dross achieving a maximum flow rate of $0.8 \mathrm{l} / \mathrm{min}$ compared to an RD which generated hydrogen at $2 \mathrm{l} / \mathrm{min}$.

The results proved that both forms of aluminium dross possess the potential to provide an acceptable volume of hydrogen at relatively consistent flow rates. The RD sample provided higher flow rates, and the LD sample generated hydrogen at a lower but consistent flow rate for a longer period and at a volume rather close to that of the RD sample. XRD analysis of the resulting product also yielded promising results with the formation of bayerite and gibbsite, which would provide additional side products of market value; if this process will be conducted on a larger scale.

Conclusions: This study has shown very promising results, with both dross samples allowing for an acceptable production of hydrogen. It has shown that the utilisation of dross can be a potentially economically viable process for a product that provides clean, renewable energy and residual aluminous products of a real market value.

Keywords: Hydrogen, Aluminium dross, Waste, Landfill, Recycling

\section{Background}

With the production of aluminium worldwide reaching almost 61 million metric tonnes in the last year, there is a real issue encountered worldwide with the residual aluminium dross produced from the industry [1]. Aluminium is a material ever present in a landfill, not only due to its high content of domestic waste, but also due to the volume of aluminous residual by-products

\footnotetext{
* Correspondence: e.elsarrag@gord.qa; elsarrag@hotmail.com Gulf Organisation for Research and Development, Qatar Science and Technology Park, Doha, Qatar
}

produced by the primary and secondary aluminium industry. In these respective industries, this waste product is known as aluminium "dross" and is produced as a byproduct of the aluminium recycling industry and the Bayer process among others. In most regions, as aluminium dross is not classified as a hazardous waste material, it is commonly directed to landfill without any pretreatment. However, there are hazards that aluminiumrich waste would pose when stored in such environments. Aluminium can remain dormant for many years until it comes into contact with a basic water source 
(such as landfill leachate with $\mathrm{pH}<7$ ) which can result from its contact with water. The aluminium and water would react vigorously to generate pockets of concentrated hydrogen in the landfill at high pressures with great risk of combustion. As a result, landfills receiving aluminous material require stringent controls to avoid the build-up of such hazardous gases. The reaction between aluminium dross and water can also result in what is known as subsurface landfill fires and smouldering combustion. This type of occurrence can be rather destructive to a landfill system as it is, in many cases, undetectable and may not generate visible smoke due to the layers of waste materials acting as particulate filters. Dealing with the disposal, monitoring and control of these potentially hazardous wastes will, in turn, cost the industry millions of dollars which has naturally incentivised the need for research and development of alternative methods to deal with aluminous dross $[1,2]$.

Aluminium dross is identified under two categories: white and black dross. White dross has generally a higher $\mathrm{Al}$ content and is typically recycled through the relevant process. Black dross contains a lower $\mathrm{Al}$ content and is therefore considered undesirable. Only white dross is typically considered for aluminium extraction as black dross, as the energy intensive extraction process is not seen as economically viable with respect to its lower aluminium content [3].

Aluminium production wastes can significantly and severely impact the operation and behaviour of a solid waste landfill, causing serious damage to gas extraction, leachate collection or liner systems. For instance, it may react exothermically with liquids, where the dissolution of salts does increase the leachate $\mathrm{pH}$ due to a reaction with metal oxides, carbides and nitrides. Furthermore, these reactions can cause waste mass instability, can initiate landfill fires and can also result in the release of nuisance odours and air emissions that may be harmful to local communities.

The standard method for retrieving aluminium from dross is known as "hot dross processing", where the white dross is ground and screened to separate the aluminium metal from the impurities. The metals are then heated to increase the aluminium melting temperature in a rotary kiln. However, due to the kiln's atmosphere which contains a mixture of natural gas and oxygen, a large amount of the aluminium can oxidise and lower the purity of the aluminium product. As a result, many extraction processes utilise salt as a flux which, due to the low melting point of the salts, encase the aluminium particles and prevent them from coming into contact with the atmosphere and oxidising. The physical extraction of aluminium from the dross is preferable to chemical methods where hazardous materials are formed as waste products of the extraction and $\mathrm{Al}$ processing, such as the release of perfluorocarbons and other harmful gases during the aluminium smelting process in addition to its impact on soil, habitats and water bodies. However, although the aluminium recovery of coarse dross particles is quite good (ranging from $90-95 \%$ of Al recovered), the dross recycling process is very inefficient in recovering aluminium for less coarse particles. As a result, around $10 \%$ of the aluminium produced by primary and secondary industries is lost as dross to landfill. This study focuses on the utilisation for this black dross by generating hydrogen for use as a fuel $[1,3]$.

Natural gas is Qatar's main contributor of energy production and consumption. However, as it is, of course, a finite source of fuel, many alternative forms of energy are being studied in order to allow for the eventual transition of renewable and clean technologies to become key contributors to the nation's energy demands. There are many options when looking at the available alternative forms of energy. However, these technologies do not provide the necessary amount of energy that could be produced from conventional forms of utilising fossil fuels. This is one of the many reasons why hydrogen is being considered as a viable fuel to take up a significant percentage of energy demands. As can be seen in Fig. 1 through the use of hydrogen as a resource, there is a potential renewable energy that possesses a substantial amount of energy per kilogram in comparison to other fuels [4].

Qatar in particular, whose population has more than tripled in the last decade, is facing an ever increasing demand for energy. As a result, there is ongoing research for the most efficient and cost-effective technology that will be able to reduce the demand for the depleting fossil fuels.

Hydrogen generation is, in fact, one of many clean technologies, and its majority is utilised by the natural gas industry which Qatar is its major producer [5]. There are many methods used in the industry to generate hydrogen such as steam reforming, particle oxidation as well as the production of hydrogen using water (electrolysis, photo-catalytic water splitting, etc.). Steam reforming is the most popular method of hydrogen production and is generally used in the natural gas industry [6]. Although steam reforming is considered the most effective method, with respect to the amount of hydrogen generated per unit, it is important to look at the technology available which could be developed to produce hydrogen with some form of long-term sustainability. As a result, a lot of attention has been turned to the possibility of producing hydrogen through the use of reactive metals, and of the metals favoured, aluminium has shown the most promise for hydrogen generation. Hydrogen production from aluminium is in fact considered to eventually reduce the demand for hydrogen from 


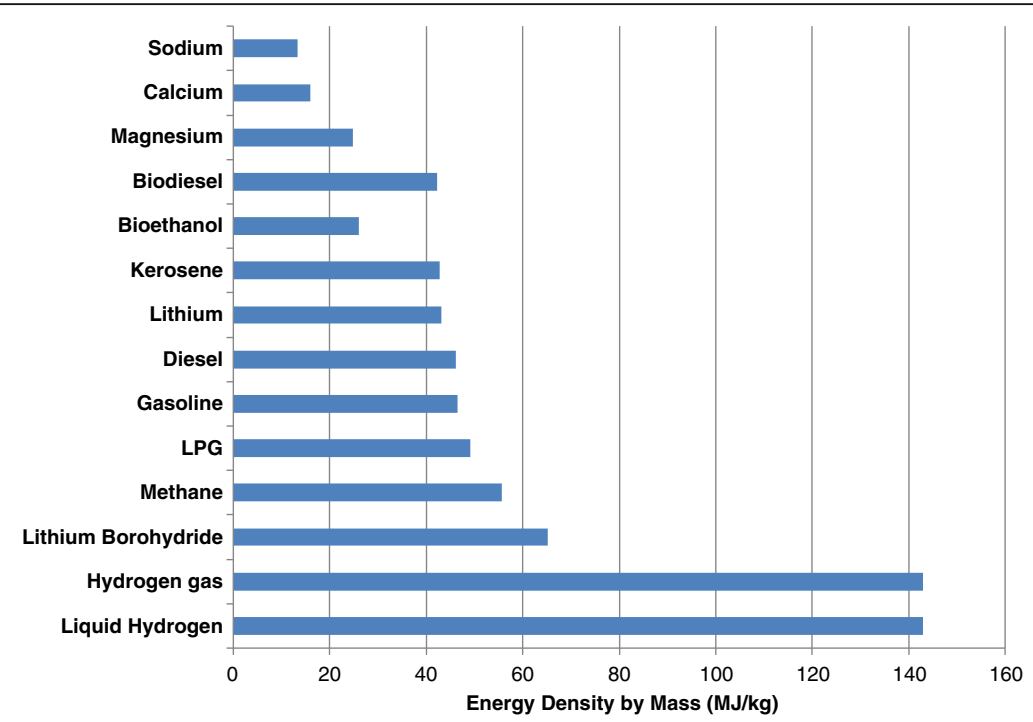

Fig. 1 Bar chart of fuel energy densities [25]

steam reforming [2]. Aluminium is used in batteries which explain its use for hydrogen generation [7]. However, the production of hydrogen from aluminium has become rather costly as it is dependent on the price at which aluminium could be purchased. This has made it an option which is much less economically attractive.

Thus, the aim of this project is to ascertain whether aluminium dross, recovered from Qatari recycling facilities and landfill, would provide significant amounts of hydrogen at substantially lower costs.

\section{Review of existing research and the way forward}

Extensive research was completed to gain a better understanding of the reactions, occurring in landfills which contain aluminous waste, leading to an uncontrollable temperature increase and the release of highly combustible hydrogen gas. A variety of solutions has been proposed including the management of leachate and a thorough analysis of the material chemistry. However, the reaction of aluminium with solutions above a $\mathrm{pH}$ of 9 produces the vigorous exothermic reactions which lead to the complications mentioned above. The control of such a potentially hazardous material in a multi-component system such as a municipal solid waste landfill is very complicated as a result. Alternative solutions which utilise the aluminium dross and redirect it from the landfill would have valuable consequences which would benefit both industry and environment $[8,9]$. Numerous studies have been conducted to obtain a complete understanding of the chemical reaction which takes place between aluminium and aqueous sodium hydroxide solution and how that would transfer to aluminium dross which contains several other elements which could affect the behaviour of the reaction. Extensive research has been conducted on the performance of the aluminium water reaction. Kravchenko et al. [3] confirmed that due to its low equivalent weight, aluminium consequently has great potential for becoming an efficient producer of hydrogen by weight. Only bettered by sodium borohydride (which generates hydrogen at $2.4 \mathrm{l} / \mathrm{g}$ ), aluminium is able to produce hydrogen at $1.245 \mathrm{l} / \mathrm{g}$. This amount, due to its very negative redox potential, will allow it reacting with water to produce hydrogen and alumina as confirmed in the equation below.

$$
2 \mathrm{Al}+3 \mathrm{H}_{2} \mathrm{O} \rightarrow 3 \mathrm{H}_{2}+\mathrm{Al}_{2} \mathrm{O}_{3}
$$

However, Stockburger et al. [10] confirmed that, as is the case with many metals, when exposed to air it will undergo passivation and as a result develop an inert layer on the metal's surface. In the case of aluminium, when coming in contact with air, it will oxidise to form a tightly adhering layer of aluminium oxide, preventing any further oxygen from penetrating the layer to reach and to react with the aluminium. This, as a result, will, of course, hinder the aluminium water reaction from generating hydrogen at the amounts confirmed by Kravchenko et al. [3]. In fact, surface passivation can occur as a result of the aluminium-water reaction itself, thus causing the reaction to limit its own yield. Many efforts were made to achieve higher yields by overcoming the aluminium oxide layer to no great avail.

Uehara et al. [11] found that hydrogen could be generated when the aluminium metal is cut under water effervescence. The hydrogen would be generated from the freshly cut surface of the aluminium, and before long, the flow rate would dip as passivation occurred on this surface. This was concluded as an impractical method to 
produce hydrogen. Although the experiment itself does serve as an example of the obstacles posed by passivation and the need for a practical method to overcome or mitigate its effects.

Shaytura et al. [12] proposed the addition of an undisclosed chemical activator which interacted with the hydroxyl groups of the Aluminium hydroxides formed during the aluminium-water reaction. The chemical activator would thereby have an effect on the pore size distribution in the oxide layer that will have formed during the reaction. This would consequently increase the permeability of the oxide layer thus increasing the volume of generated hydrogen. They concluded that these results could be used not only for the generation of high purity hydrogen from such reactions, but also for the development of the undisclosed chemical activators to be used as a solid oxidation product.

Watanabe [13] investigated the effect on the aluminium-water reaction when using activated aluminium powder. This activated $\mathrm{Al}$ powder, with sizes at the micron and submicron range, was prepared through mechanical grinding. It was concluded that the resulting micro-cracks contained radical $\mathrm{Al}$ atoms with one or two free bonds, which would then react with the water molecules to initially produce $\mathrm{AlH}_{3}$ and react further with the $\mathrm{H}_{2} \mathrm{O}$ molecules to produce $\mathrm{H}_{2}$.

Alinejad and Mahmoodi [14] studied the possibility of generating hydrogen from the aluminium-water reaction through the use of highly activated aluminium. Aluminium powder was activated by being milled with sodium chloride. On average, this method was able to generate hydrogen at a flow rate of $75 \mathrm{ml} / \mathrm{min}$ when the reactants were prepared at a $\mathrm{NaCl} / \mathrm{Al}$ molar ratio of 1.5 . The reactions reached a $100 \%$ yield after a reaction time of $40 \mathrm{~min}$, and the resultant dross typically contains $1-2 \%$ $\mathrm{NaCl}$ and $\mathrm{KCl}$ by weight.

Parker and Baldi [15] proposed a method for generating hydrogen via the reaction mixtures of finely divided aluminium and finely divided magnesium with seawater at normal temperature and pressure. This process was intended to produce hydrogen with by-products of aluminium hydroxide and magnesium hydroxide for their respective reactants. These by-products are particularly useful as they have a high demand for their uses as fire retardants as well as in thermal and electrical insulation.

Macanas et al. [16] suggested that the addition of inorganic salts would be able to substantially increase the yield of hydrogen generated during the reaction. Of the compounds tested, $\mathrm{NaOH}$ was in fact found to provide a $100 \%$ yield increase and to produce at least $1.5 \times$ more hydrogen than the other salts tested (e.g. $\mathrm{Na}_{2} \mathrm{SO}_{4}$, $\mathrm{MgCl}_{2}, \mathrm{FeCl}_{3}$, etc.).

Soler et al. [17] observed that the effect caused by surface passivation could be minimised when operating the reaction at optimum parameters. Soler et al. found the optimum temperature for the reaction to be at $340-360^{\circ} \mathrm{C}$. They experimented with effects of $\mathrm{NaOH}$ compared to $\mathrm{KOH}$ at a concentration of $1-5 \mathrm{~mol}$ and temperatures between 290 and $350 \mathrm{~K}$. It was concluded that maximum hydrogen production per gram of aluminium was reached at 5 mols of $\mathrm{NaOH}$ at $350 \mathrm{~K}$ with a flow rate of $3100 \mathrm{~cm}^{3} / \mathrm{min}$. Five moles of potassium hydroxide at $350 \mathrm{~K}$ generated hydrogen at a flow rate of $2900 \mathrm{~cm}^{3} / \mathrm{min}$ per gram of aluminium.

In addition to this, Soler et al. [18] investigated the effect of sodium aluminate on the reaction. This gave results comparable to $\mathrm{NaOH}$, i.e. similar values in terms of the yield of the reaction, and the maximum flow rates were achieved. This could be attributed to the presence of $\mathrm{Na}$ in the reaction and left doubt as to whether aluminate had any chemical effect on the reaction.

In comparison to the manufactured aluminium, the utilisation of waste aluminium has not garnered much attention. The findings of studies with regard to aluminium dross will always be differently dependent on the region from which the samples of waste aluminium were taken. Nevertheless, there exist a number of reported studies. Silva-Martinez et al. [19] were able to utilise aluminium waste cans to produce $0.049 \mathrm{~mol}$ of hydrogen per gram of aluminium ( 2 mols of $\mathrm{NaOH}$ for each run). Hiraki and Akiyama [20] also devised a system which found that the energy of even aluminium dross containing around 15\% aluminium was still large.

This paper covers the effect of luminous black dross on the aluminium-water reaction and the effect that $\mathrm{NaOH}$ has on it. By taking into consideration the percentage of aluminium present in each sample, the same molar weight of aluminium would be used and thus would allow for a fairer comparison. Thus, as the same amount of aluminium will be present when comparing with each molar quantity used, the effect that the other dross elements have on the process could be ascertained.

\section{Theory of hydrogen production from Al waste}

The chemical reaction which takes place for pure aluminium is as follows:

$$
\begin{aligned}
& 2 \mathrm{Al}+2 \mathrm{NaOH}+6 \mathrm{H}_{2} \mathrm{O} \rightarrow 2 \mathrm{NaAl}(\mathrm{OH})_{4}+3 \mathrm{H}_{2} \\
& \mathrm{NaAl}(\mathrm{OH})_{4} \rightarrow \mathrm{NaOH}+\mathrm{Al}(\mathrm{OH})_{3} \\
& 2 \mathrm{Al}+6 \mathrm{H}_{2} \mathrm{O} \rightarrow 2 \mathrm{Al}(\mathrm{OH})_{3}+3 \mathrm{H}_{2}
\end{aligned}
$$

It can be seen that (3) is the global reaction of steps (1) and (2). In step (1), 2 mols of $\mathrm{Al}$ and $\mathrm{NaOH}$, as well as 6 mols of water react to produce 3 mols of hydrogen with a 2 mols by-product of $\mathrm{NaAl}(\mathrm{OH})_{4}$. Although, the reaction is not one which eventually reaches equilibrium, 
due to the fact that the $\mathrm{Na}$ reacts so vigorously, the low concentration of $\mathrm{NaOH}$ will be regenerated in step (2).

The Na here is used as a catalyst, and the aluminium hydroxide recovered from the compound can be a useful by-product and could be used to produce a hydrated sodium aluminate. This would prove to make the reaction's by-product highly useful and even profitable.

However, the source of aluminium being used in this experiment is not pure and is in fact recovered from landfill or is recycled material. This means that the aluminium used in this paper will contain alternative materials which will affect the reaction. There could also be elements which would have reacted with the aluminium and could also significantly affect the reaction. An example of which would be the compound of aluminium oxide. When aluminium is exposed to air, its surface will be oxidised by forming a tight outer layer aluminium oxide. If the aluminium metal would have formed an oxide coating, it would interfere and slow down the reaction.

Provided the aluminium metal did not have a coating of aluminium oxide on its surface, then it would react with water just as vigorously as sodium metal does. The aluminium oxide coating, however, is amphoteric, which means that it is able to react with both acids and alkalis. This would mean that a strong alkali such as sodium hydroxide would react with it, although the reaction would have a much slower start which could be contributed to the oxide layer it may have [21-23].

Sample digestion was utilised in order to identify the other elements present in each of the sample (results can be seen in Fig. 3). The elements identified were all metals, which will have a tendency to react in quite the same way as the Al. This would naturally mean that these metals would have the potential to interfere with the oxidation of aluminium. This will also mean that other reactions will take place which might result in the presence of impurities (e.g. hydroxides and metallic cations) in the obtained reaction product. The effect that this could have on the reaction will, of course, depend on the percentage of each product in the sample. If the element is in small concentration, which is the case for most of the elements, it will not have a significant bearing on the overall reaction. In the LD sample, there is a larger percentage of $\mathrm{NaOH}$ than in $\mathrm{Al}$. This would not affect the reaction significantly, as the $\mathrm{Na}$ reacts more vigorously than $\mathrm{Al}$ it could produce higher quantities of $\mathrm{NaOH}$, resulting in excess reactant.

\section{Methods}

Two different kinds of waste aluminium to be used for experimentation are recycled (RD) aluminium or (LD) aluminium recovered from a landfill. The two samples were initially sent to external laboratories to ascertain the composition of each and to confirm what percentage of aluminium would be found. Once the composition was received back from the laboratories, the samples had then used in the reaction to confirm their respective flow rates at different concentrations of the reactants. The concentration had to be changed for both the aluminium samples and the sodium hydroxide in order to confirm how each reactant would affect the productivity of the reaction. In order to measure the flow rate of the reaction, the apparatus was set up as shown in Fig. 2.

The generation of hydrogen was measured through the use of a simple water displacement method. The experiment consisted of two gas-tight flasks (numbered 1 and 2 for reference) and a water collection tank. The dross reactant reacted with an aqueous solution of concentrated $\mathrm{NAOH}$ in flask 1 to release hydrogen to pass through to flask 2 . The produced gas had to pass a rotameter to measure its flow rate prior to entering flask 2 .

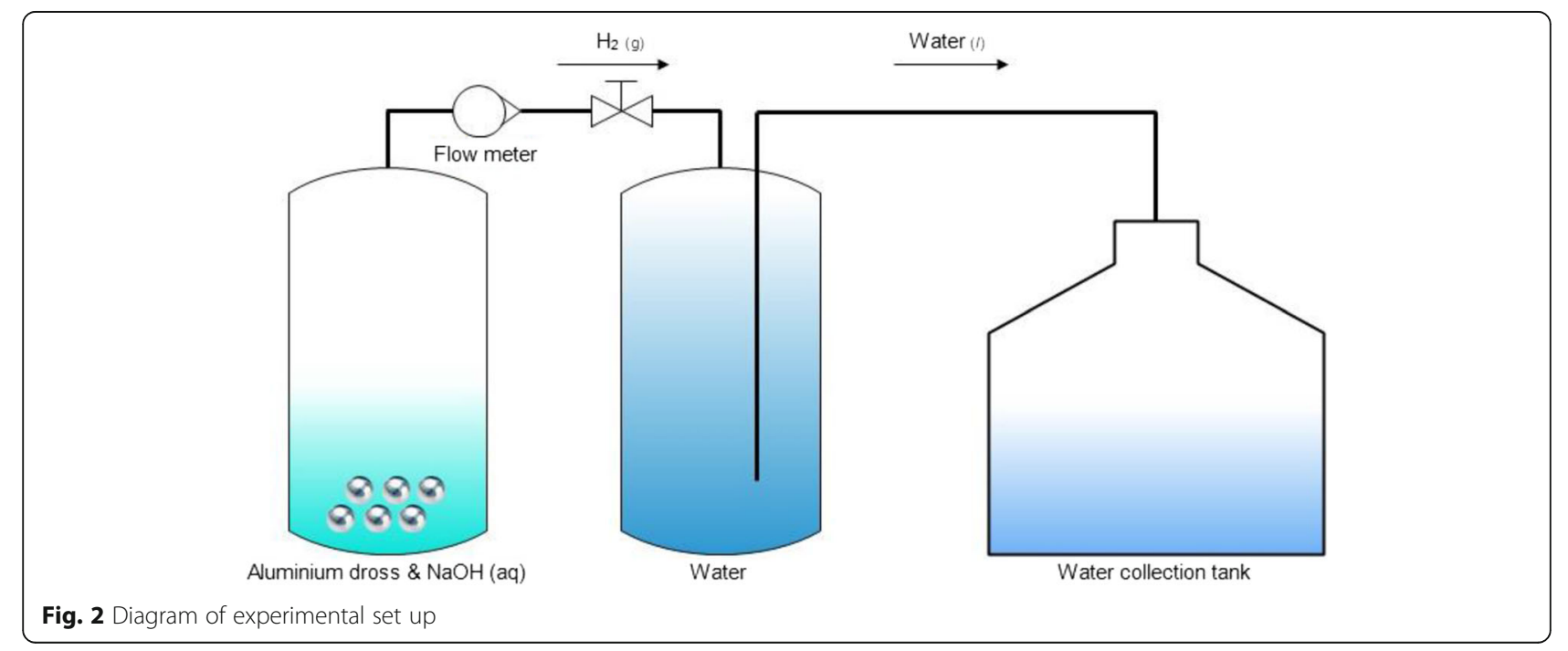


The second flask is filled with distilled water and was set up in a way, so that any gas that enters the flask would displace the water within the flask and would pass through the tube into the water collection tank. The weight of the water collection is constantly monitored and is recorded at pre-determined time intervals. The molar quantities used for each sample would take into consideration the amount of aluminium present and hence use enough of the sample which would provide the required moles of aluminium. The maximum molar amount of $\mathrm{Al}$ used per experiment was limited to $0.5 \mathrm{~mol}$; mainly because higher moles of $\mathrm{Al}$ would result in reactions with excessive heat release resulting in temperatures that the apparatus could not withstand.

The characterisation techniques used included Chemical Digestion to provide a quantitative analysis of the elemental composition of the dross samples. Powder Xray Diffraction analysis was also carried out to obtain a qualitative analysis of both the solid dross reactants and products.

These samples were analysed using a PANalytical Empyrean with a strictly monochromatic $\mathrm{CuK} \alpha 1$ radiation set at a wavelength of $1.54056 \AA$ under tube operating conditions of $45 \mathrm{kV}$ and $40 \mathrm{~mA}$ with soller slits of $0.04 \mathrm{rad}$. The data was acquired from 0-60 degrees resulting in a runtime of 105 mins.

\section{Results and discussion}

Initially, both the RD and LD samples were analysed, as shown in Fig. 3, to confirm the percentage of $\mathrm{Al}$ present as well as its elemental composition.

It can be observed that the RD aluminium has a substantial amount of $\mathrm{Al}$ which of course proved to be highly useful for hydrogen generation. The landfill aluminium, however, possessed a higher than the expected amount of $\mathrm{Al}$ which was very promising. Compared to the $\mathrm{Al}$ which would need to be purchased from the recycling plant, this is due to the fact that it is available at no charge as it is being recovered from a landfill site and is deemed a waste. If the landfill aluminium did provide a good return of hydrogen, it would become a very attractive prospect. The other elements found at significant percentages were calcium and sodium in the landfill sample. Calcium is common in the region and can be found in material such as rocks, however, typically the dross contains $\mathrm{Na}$ and $\mathrm{Ca}$. As sodium is so reactive, it will likely be found in a compound with the aluminium.

A powder XRD analysis was also completed to analyse the phase composition of the aluminium dross samples before they reacted in the alkaline solution. The XRD diffraction patterns alone could only provide qualitative results, however, when used in tandem with the elemental composition of the chemical digestion analysis, it would be possible to develop a more accurate picture of the reactants' compositions. (Fig. 4)

The diffraction patterns of both samples showed that the phase compositions differ only in proportion with the major phases of $\mathrm{Al}_{2} \mathrm{O}_{3}, \mathrm{Na}_{3} \mathrm{AlF}_{6}, \mathrm{Na}_{5} \mathrm{Al}_{3} \mathrm{~F}_{14}$ and $\mathrm{Na}_{2} \mathrm{Ca}_{3} \mathrm{Al}_{2} \mathrm{~F}_{14}$ existing in both samples (Fig. 5). These phases are all commonly found in aluminium production dross. The presence of alumina available in both samples was that of the $\alpha-\mathrm{Al}_{2} \mathrm{O}_{3}$ polymorph, also known as a corundum. $\mathrm{Na}_{3} \mathrm{AlF}_{6}$ and $\mathrm{Na}_{5} \mathrm{Al}_{3} \mathrm{~F}_{14}$, known as cryolite and chiolite, respectively, are commonly present in the Bayer process. The main concern about the raw material is the

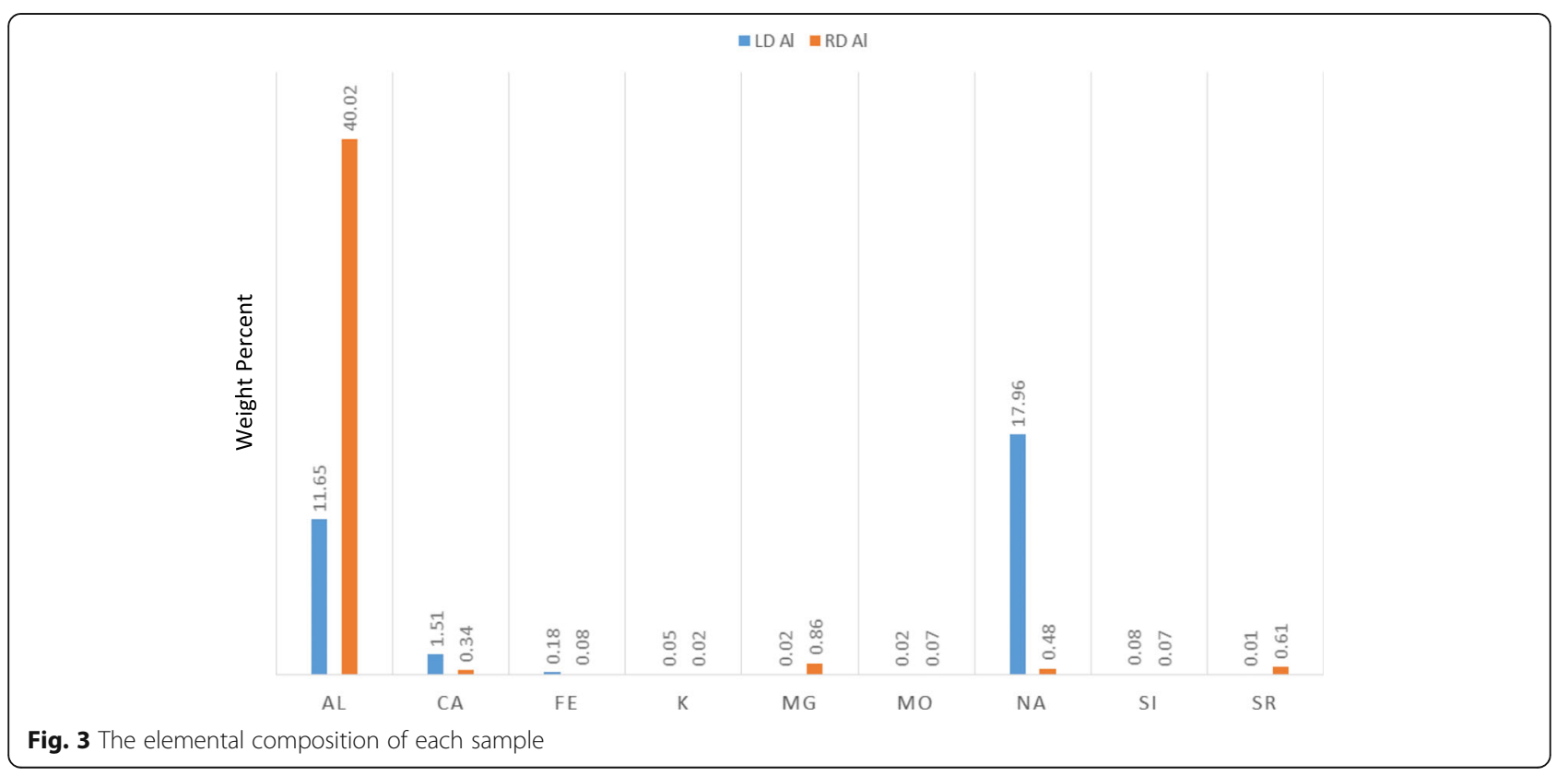




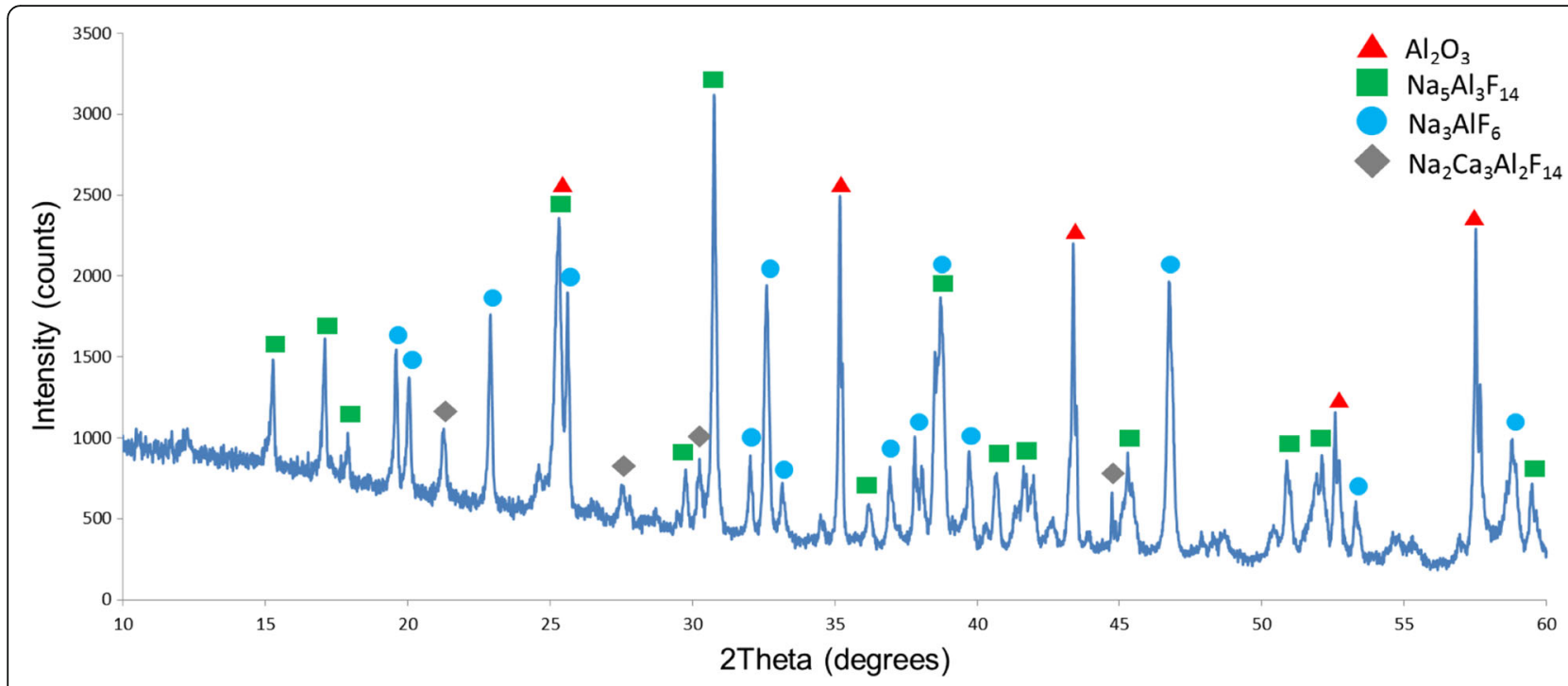

Fig. 4 X-ray diffraction pattern of the LD dross

presence of the fluorine in the raw material as it is likely to form HF as it is very corrosive and may later damage the unit operations if the process was to be carried out on a larger scale. Consequently, the concentration of $\mathrm{NaOH}$ can be adjusted in order to neutralise the HF and avoid any dangers of corrosion.

Further XRD scans were also carried out on the products obtained after the reactions. The diffraction patterns of these products can be seen in Figs. 6 and 7.

The product diffraction patterns exhibit positive results, as there were no signs of hazardous waste material as major phases in the solids at least. Bayerite
$\left(\alpha-\mathrm{Al}(\mathrm{OH})_{3}\right)$ and gibbsite $\left(\gamma-\mathrm{Al}(\mathrm{OH})_{3}\right)$ are products which could have a variety of uses as they are commonly being used in the pharmaceutical industry. The $\mathrm{Al}(\mathrm{OH})_{3}$ could potentially be precipitated from these products in a similar method to what is done with "red mud" $\left(\mathrm{Al}(\mathrm{OH})_{3}\right.$ containing waste product) in the Bayer process.

As mentioned in the experimental procedure, the concentrations of both reactants were changed for each run to compare their effects. Figure 8 demonstrates the hydrogen generated for both the RD and the landfill aluminium at each molar ratio.

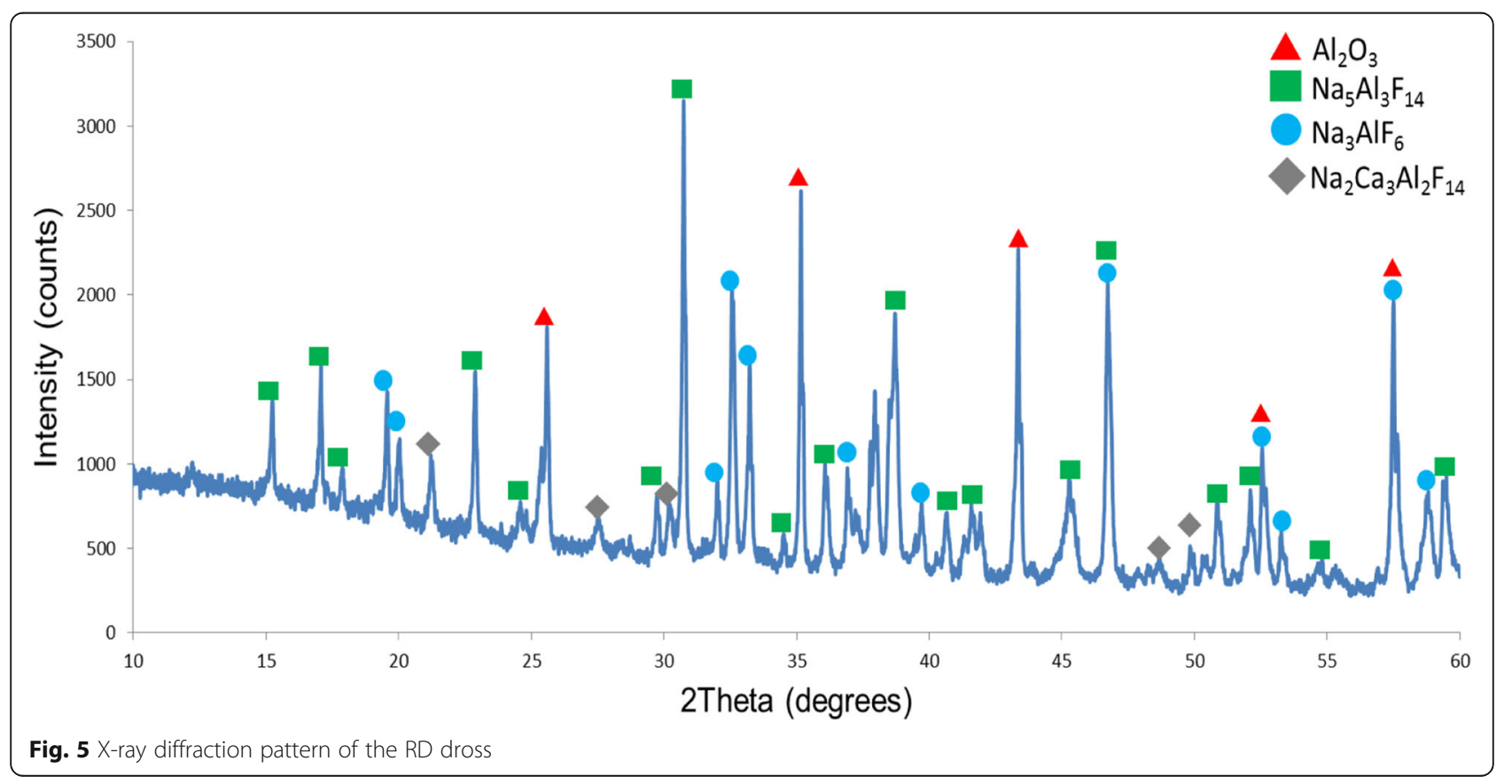




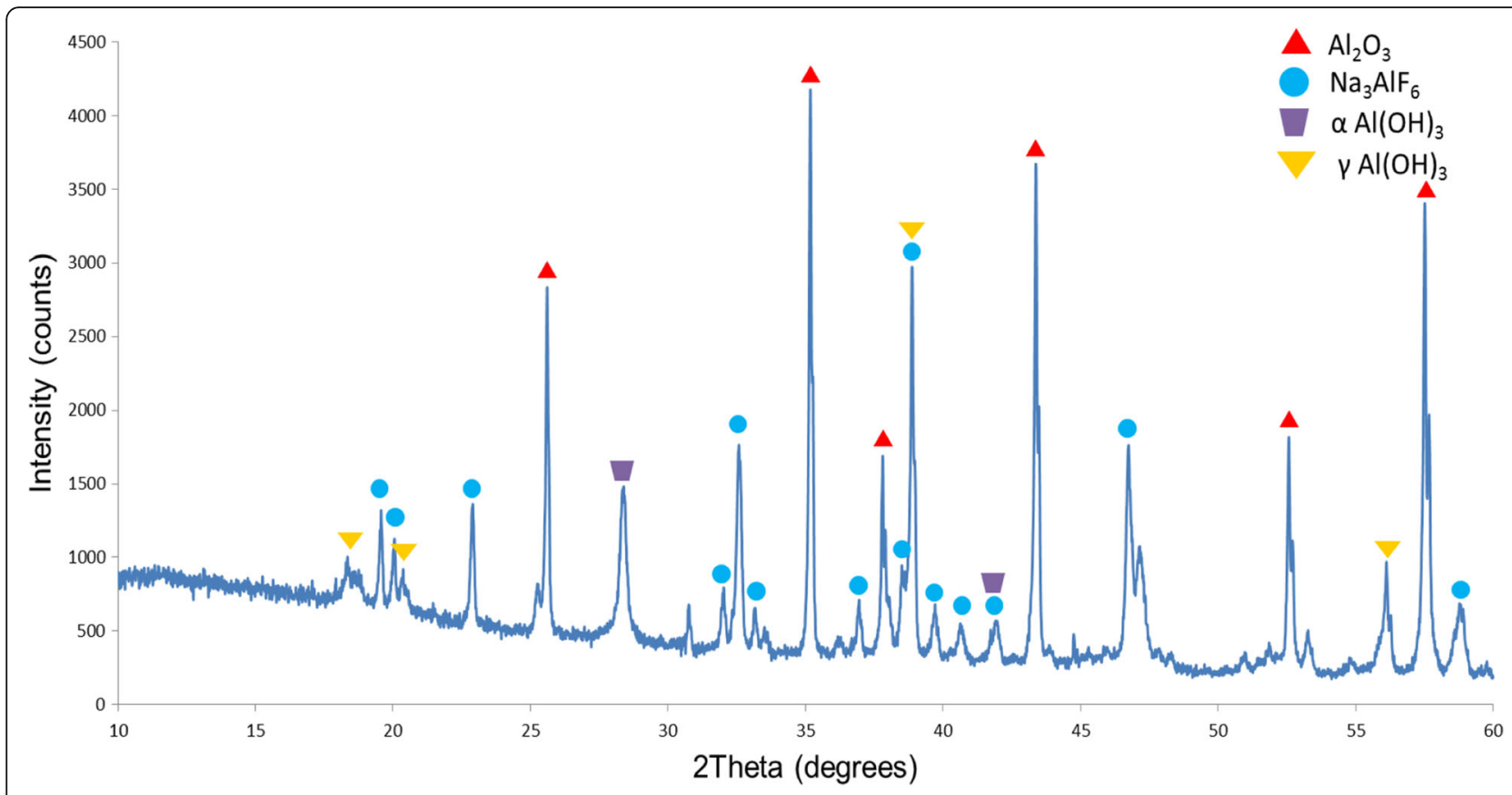

Fig. 6 X-ray diffraction pattern of LD reaction products

The volume generated by the RD aluminium dross was much higher than that of the dross recovered from landfill which is of course due to the higher percentage of aluminium found in that sample compared to the landfill dross. What is promising, however, is that the volumes achieved by the LD aluminium are not lagging too far behind that of the RD aluminium at all. Although the volume collected for the RD aluminium rises rapidly as it reaches equimolar concentrations, the LD aluminium is still able to rise at a good gradient especially considering that the sample was recovered from a source where it was considered a waste and would no longer be used. We can also see from this graph that, at a lower concentration of sodium hydroxide, the reaction will produce less hydrogen. This was also expected, as the concentration of $\mathrm{NaOH}$ will have a

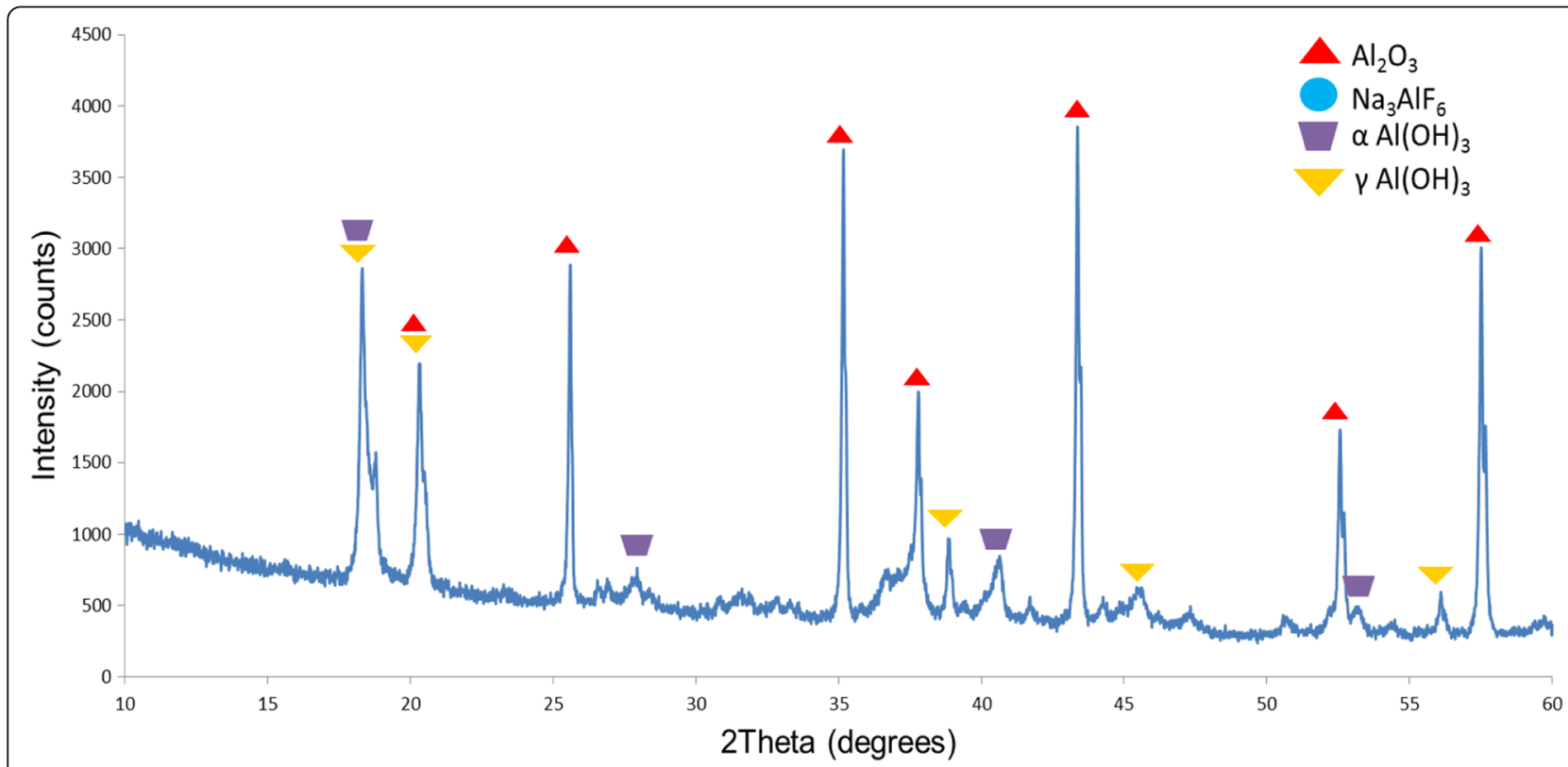

Fig. 7 X-ray diffraction pattern of RD reaction products 


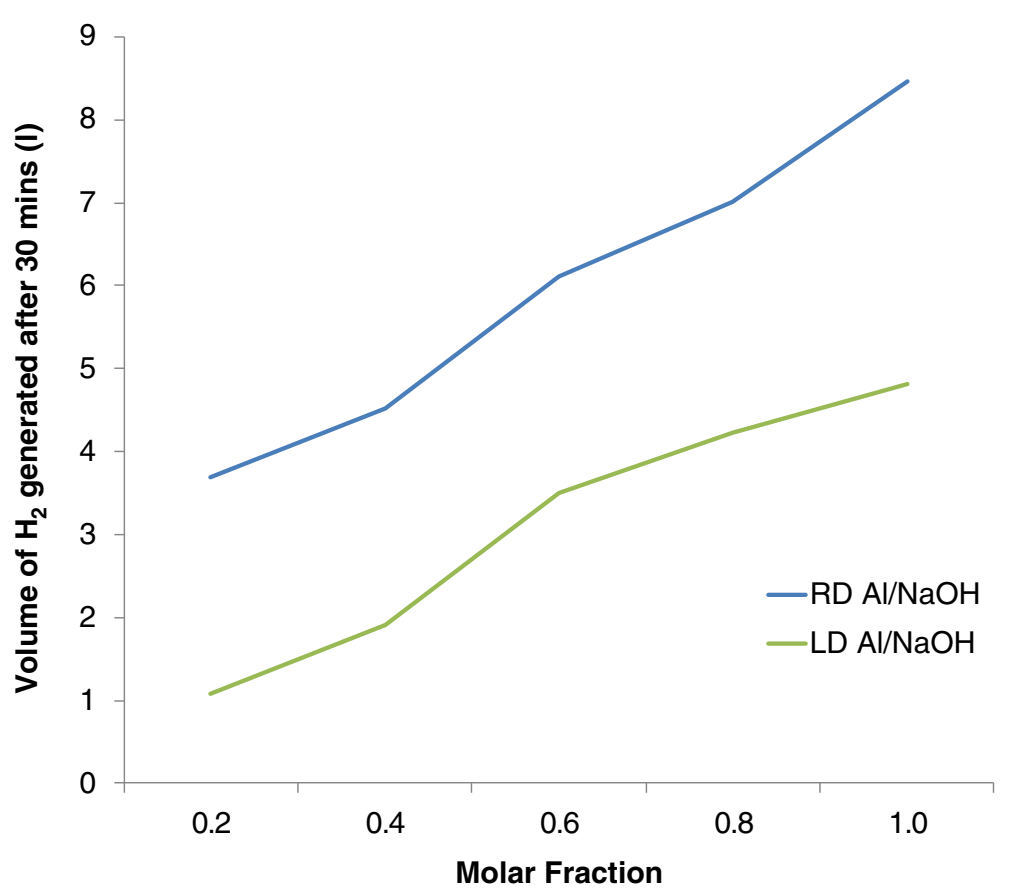

Fig. 8 Progression of flow rates at different reactant concentration

large bearing on the penetration of the oxidised layer that would have been present in the aluminium samples. It can be observed from this graph that reducing $\mathrm{NaOH}$ will substantially decrease the reaction kinetics. As mentioned before, when measuring the volumes of hydrogen generated by each reaction, the measurements were taken from the first hour of the reaction, as it was observed that it was during this period that the reaction reached its peak flow rate. The peak flow rate for all the experiments would typically be reached within the first $30 \mathrm{~min}$. Below is a graph of the flow rates recorded for the first hour of the reaction of each sample at equimolar concentrations. It is worth noting that there is no gas analysis conducted at this stage.

Figure 9 shows that both samples reached their peak flow rates within the first $25-30 \mathrm{~min}$ of the reaction. The RD sample from the beginning is able to yield flow rates around three times the flow rates of the LD sample. The RD sample, however, has a substantial

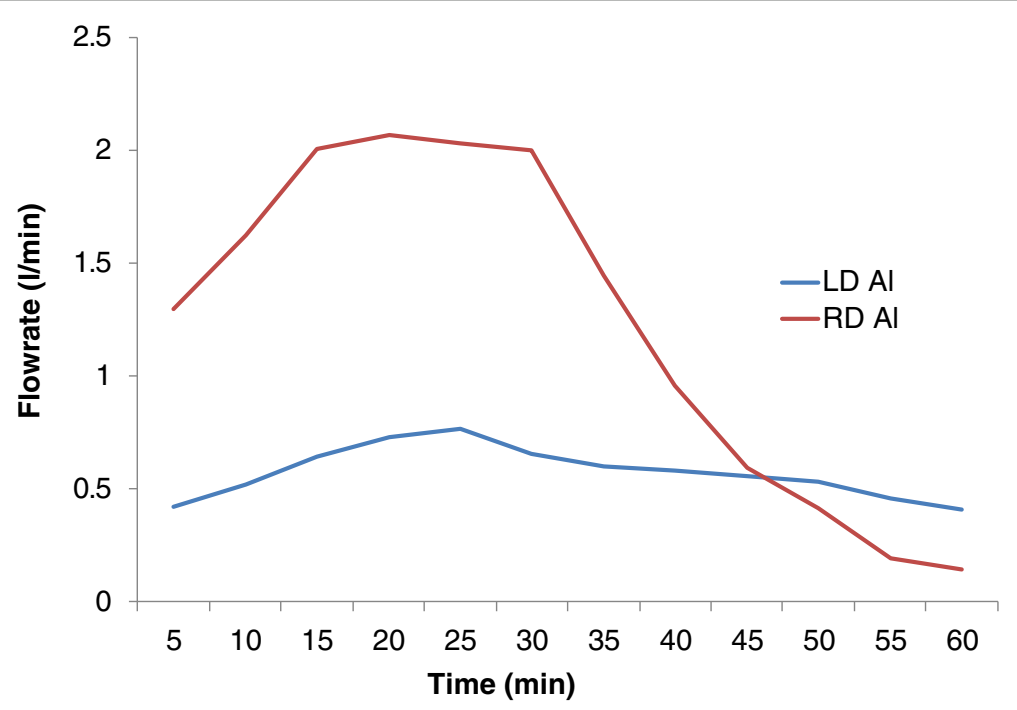

Fig. 9 Flow rates of generated hydrogen in the first hour 
reduction in its generation after the first $30 \mathrm{~min}$ and drops to a flow rate less than half of that of the LD aluminium. The flow rate of the LD aluminium, on the other hand, has a relative steady flow with a drop to two thirds of its peak flow rate at the hour mark; eventually reaching a flow rate marginally lower than the flow rate recorded after the first $5 \mathrm{~min}$ of the reaction. To avoid differences in performance due to the aluminium surface area, the experiments were conducted using similar sizes of granules and smaller ground granules for both types of dross but of the aluminium particles in LD compared to the RD. However, there is a level of uncertainty, so that the LD provides more surface area than RD due to uneven granules.

Figure 10 shows an accumulation of the amount of hydrogen generated over the period of $1 \mathrm{~h}$. It shows that the rate at which the hydrogen is generated varies between the two samples at 0.5 mols. The RD sample generated hydrogen at more than 1.5 times the rate of the LD sample. From around the 30th minute, the rate of hydrogen generated using the RD sample becomes lower than that of the LD sample. The RD sample's reaction rate eventually settles at around $96 \%$ of the rate of the LD sample. Throughout the first hour, the recorded reaction rate of the LD sample stays relatively steady. When observing the trends in Fig. 10 in conjunction with the trends of the reactions' flow rates shown in Fig. 9, it can be seen that the RD sample is able to produce much higher flow rates and generally shows much more promising kinetics in the first hour. The difference in the reactivity between the two samples can be attributed to the difference in the aluminium present in each sample. Due to the fact that the RD samples contained more aluminium per gram of dross, it meant that a smaller amount of material would be needed to provide the same amount of dross as the LD sample. This, in turn, provides a material with a much larger surface area, improving its reactivity in this way.

Additional runs, at a ratio of $2 \mathrm{NaOH}: 1 \mathrm{Al}$, were also completed in order to compare each sample with the manufactured $\mathrm{Al}$ used by Elsarrag [24]. It was confirmed that $1 \mathrm{~g}$ of manufactured aluminium generated around $350 \mathrm{ml}$ of hydrogen after $30 \mathrm{~min}$. For the runs completed, $1 \mathrm{~g}$ of $\mathrm{Al}$ was used for both samples at the same ratio. For $1 \mathrm{~g}$ of $\mathrm{Al}$, after $30 \mathrm{~min}$ the $\mathrm{RD}$ and $\mathrm{LD}$ samples would generate around 147.8 and $58.4 \mathrm{ml}$, respectively. These volumes are of course significantly less than what would be produced from manufactured aluminium. However, it must be remembered that the RD and LD samples contain 40 and $11.65 \%$ of $\mathrm{Al}$ by weight, respectively. If the process were to be used on a larger scale, an additional extraction stage could be added in order to improve the yield of hydrogen.

After having measured the flow rates and the volume at each stage of the reaction, the theoretical volume was calculated in order to confirm the accuracy of the results obtained from the reaction.

In the histogram shown in Fig. 11, we can see the comparison between the actual volume and the calculated theoretical volume of each sample for the corresponding amount of moles of aluminium used. There is a visible difference between the theoretical and actual volumes recorded. The difference may be due to a possible leak coming from the apparatus, although the difference is small enough to confirm that the measurements carried out for each sample were indeed correct. We can also observe that although the LD sample outputs lower flow rates, its reaction runs for a much longer time until it eventually has provided a volume close to that of the RD sample. With the larger amount of undesirable phases

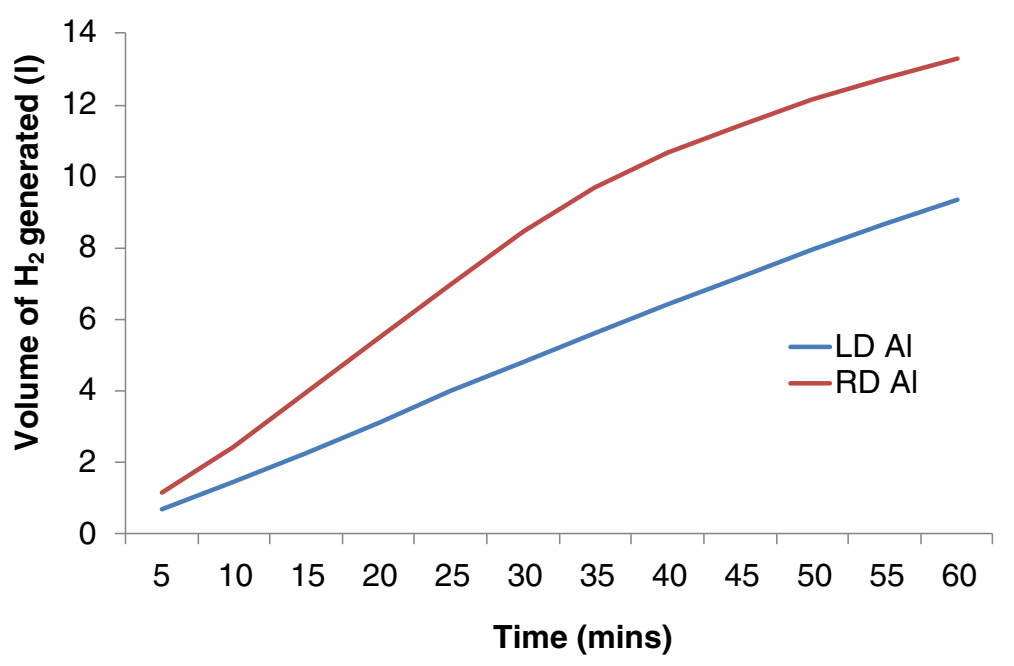

Fig. 10 Cumulative volume of hydrogen generated in the first hour 


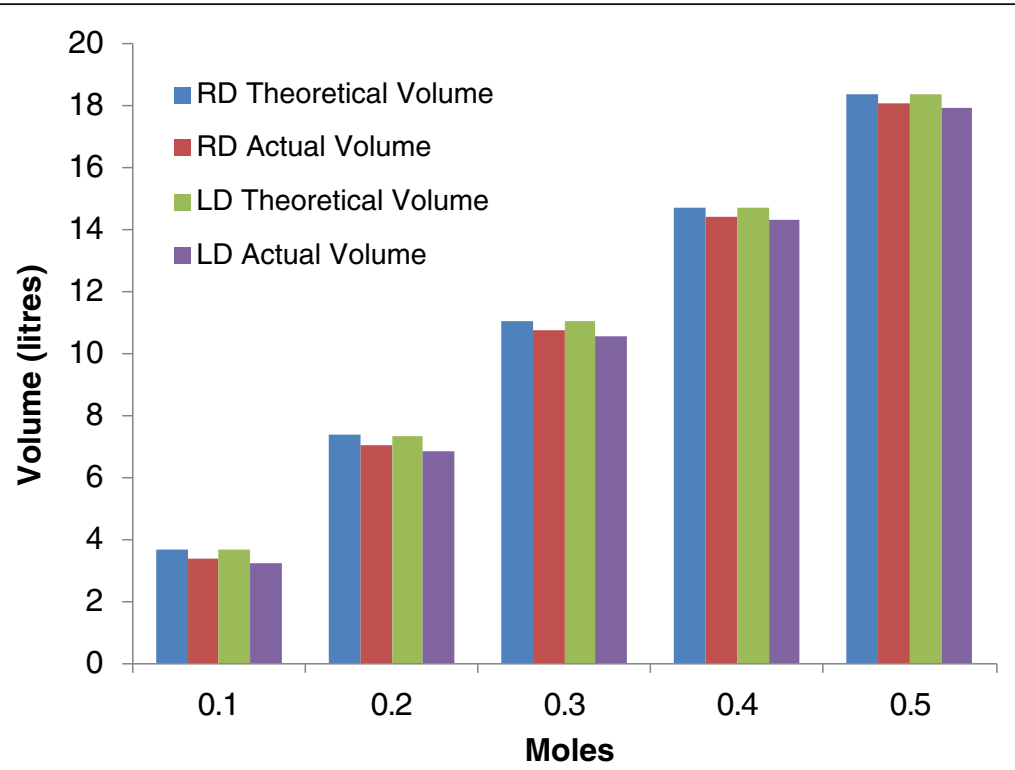

Fig. 11 Histogram demonstrating the difference between the estimated generated volume and the measured volume generated from the RD and LD samples

present in the LD sample, it is still able to produce results similar to the higher purity RD sample.

In order to improve the reaction rate of the experiment, the dross samples were ground as compared with the original particle sizes in those samples. As expected, the particle size of the dross differed widely from fine powder to large chunks. The aluminium dross samples were ground to a maximum particle size of $5 \mathrm{~mm}$ diameter. These comparisons can be seen in Figs. 12 and 13 . The ground samples are shown as "granular" in the graphs, whereas the plots are shown as normal RD/LD are the variable grain sizes in which the dross was received.
Both dross samples exhibited a substantial increase in their hydrogen yield instantly at the start of the reactions. It was ensured that a minimal period of time was allowed between the grinding of the sample material and the reaction with the alkali solution. This was to ensure that ground material would not be allowed to gain a thick aluminium oxide layer which would cause the delay in the experiment that can be seen in the previous experiments. This is also exhibited by the peak flow rate being at the very beginning of the reactions with the low particle sizes. The reason for the delay in the peak flow rate of the original samples was due to the thick aluminium oxide layer that developed over time. This layer

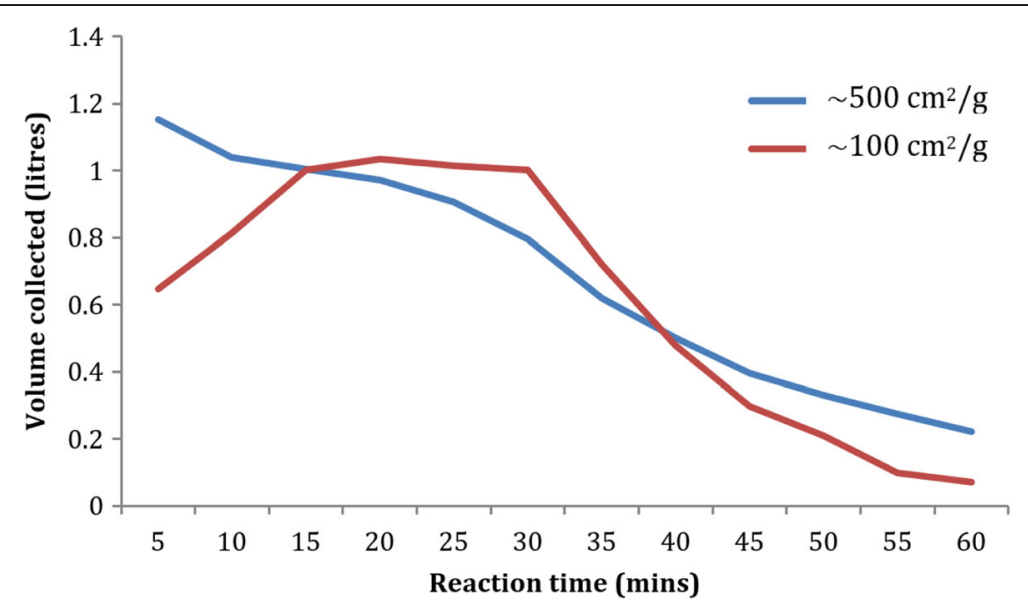

Fig. 12 Volume of hydrogen collected at 5 min intervals for an hour for both the original and the grinded material of the RD sample at equimolar quantities of $\mathrm{Al}$ and $\mathrm{NaOH}$ 


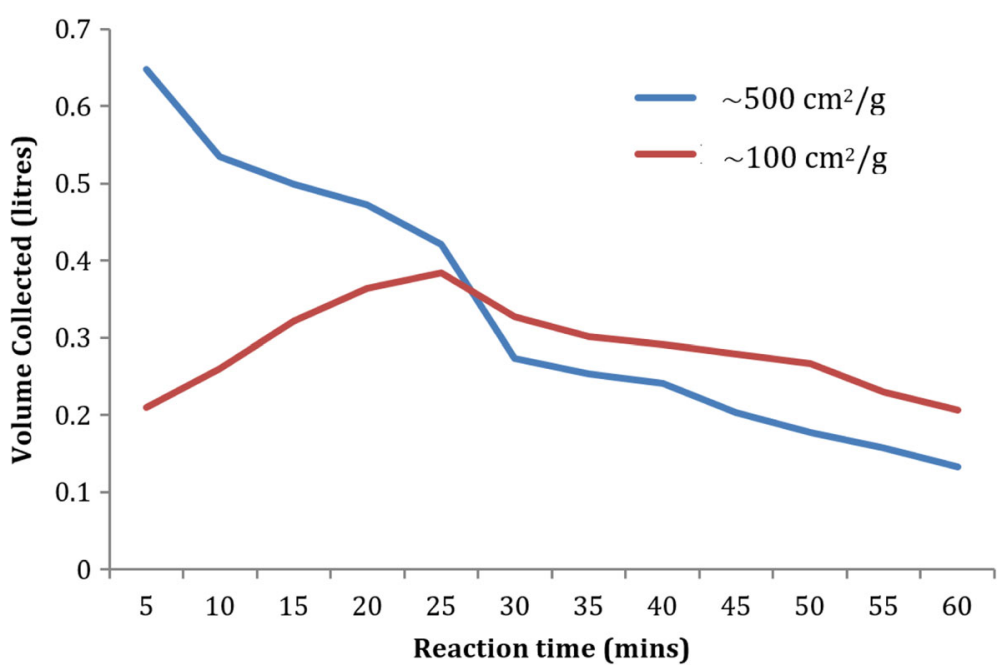

Fig. 13 Volume of hydrogen collected at 5 min intervals for an hour for both the original and the grinded material of the LD sample at equimolar quantities of $\mathrm{Al}$ and $\mathrm{NaOH}$

could not be fully penetrated until after the first $25 \mathrm{~min}$ of the experiment.

In addition to this, with the increased surface of the material, the kinetics of the experiment were massively improved with the RD dross sample generating double the amount of hydrogen in the first $5 \mathrm{~min}$ and the LD sample producing over triple the amount. After the first $5 \mathrm{~min}$, both samples would then drop to similar flow rates as those of the original particle size samples. One of the major benefits of the improvement of reaction rate, with the smaller particle size, is because the black dross that the aluminium recycling industry deems not to be cost-effective are those that are small in particle size. These samples would be effective for the generation of hydrogen, and with an additional pre-grinding stage could be made to be more reactive.

Both the RD and LD samples showed good potential as they provided a sufficient return of hydrogen when considering the percentage of $\mathrm{Al}$ present in each. Both samples were able to produce approximately $0.5 \mathrm{l}$ of hydrogen per gram of aluminium and $0.15 \mathrm{l} / \mathrm{g}$. These yields could be improved if the samples were ground as well.

Table 1 The volume of hydrogen generated per g Al reported in the literature compared to LD and RD

\begin{tabular}{ll}
\hline & Volume (I) $\mathrm{H}_{2}$ per gram of Al \\
\hline Elsarrag [24] & 0.35 \\
Kravchenko et al. [3] & 1.245 \\
Uehara et al. [11] & 1.236 \\
Silva-Martinez et al. [19] & 0.049 \\
LD & 0.15 \\
RD & 0.5 \\
\hline
\end{tabular}

Although it would be difficult to de-convolute the variables involved in obtaining all these reported values, there is a degree of significance to gain from analysing the "effectiveness" of hydrogen generation from LD and RD within the context of the reported literature. It must be noted that the reported values displayed in Tables 1 and 2 are of experiments using aluminium or aluminium alloys of much higher purity except Silva-Martinez et al. [19] and Elsarrag [24], who used waste cans.

When compared to the volume of hydrogen generated per gram of $\mathrm{Al}$ (shown in Table 1), as reported by Kravchenko et al. [3] and Uehara et al., the dross samples allowed less than half of the volume to be generated. The landfill underperforms in comparison, producing almost a tenth of what was achieved by the respective investigators above. But it can also be observed that the ratios of the manufactured $\mathrm{Al}$ production rate compared to those of each of the samples are very close to the ratio of $\mathrm{Al}$ to the dross in each sample. However, both dross samples performed considerably better than the value reported by Silva-Martinez et al.

Table 2 The maximum flow rate of hydrogen generation achieved reported in the literature in comparison to that achieved with the dross samples

\begin{tabular}{ll}
\hline & Max flow rate $(1 / \mathrm{min})$ \\
\hline Soler et al. [17] & 3.1 \\
Macanas et al. [16] & 2.9 \\
Mahmoodi et al. [14] & 0.7 \\
LD & 0.8 \\
RD & 2 \\
\hline
\end{tabular}


[19] and Elsarrag [24], who used waste cans as a source of aluminium.

This substantial gulf between the dross materials and the reported aluminium/alloys, shown in Table 2, was not observed when considering the maximum flow rate achieved by the reaction. The recycled dross allowed a maximum flow rate to be obtained not considerably differing from that which was reported by Soler et al. [17] and Macanas et al. Mahmoodi et al. [14] used an aluminium-bismuth alloy to achieve the maximum flow rate shown in Table 2, a flow rate which was surpassed by the low purity aluminium dross (LD) redirected from landfill.

As shown by the results, with the reduction in particle size and an increase of dross material use, the dross samples could produce more hydrogen than that which has been reported in Tables 1 and 2. What also had to be taken into consideration is the cost of the raw materials needed to produce the hydrogen. The LD sample may have required the largest amount of material to provide the necessary moles of aluminium needed for the reaction, but it was also a very cheap source as it was being directed to landfill. The RD sample also requires more material than in the case of pure aluminium, however, at a lower cost as it was due to be passed through a recycling facility. These samples could potentially be cheaper sources of hydrogen gas with promising performances.

\section{Conclusions}

This study has shown very promising results, with both dross samples allowing for an acceptable production of hydrogen. It has shown that the utilisation of dross can be a potentially economically viable process for a product that provides clean, renewable energy and residual aluminous products of a real market value. The RD sample had rather high percentage aluminium compared to the LD dross which is attributed to its higher flow rate output of hydrogen, and it certainly does provide a cheaper alternative to purchasing pure aluminium. The LD dross, on the other hand, provides a potentially gratis alternative source of aluminium as a dross producer expected to pay large amounts in order to landfill their aluminium dross and would be a free or a cheaper alternative to be rid of their waste. When comparing the two samples, LD expectedly did not reach the flow rates as the equimolar concentrations of RD sample had reached. The LD sample, however, when processed at acceptable flow rates allowed to be substantially improved when the sample was ground down to a smaller particle size. In addition to these results, the presence of bayerite and gibbsite in the powder diffraction patterns also shows a promise as these phases could add a viability of the process to the market and also exhibits its recycling potential for aluminium dross. Further studies of this reaction should be conducted, however, as there is a risk of the effluent gases to have a corrosive effect on the later unit operations if the gas were to be perhaps used as a feed to a fuel cell operation. This process has a real potential to be used as a unit operation addition to deal dross waste streams in aluminium smelting plants, recycling facilities, etc. To fully understand the feasibility of this process for the use on a large scale, life cycle assessment and cost analyses should be carried out to confirm the economic viability and potential environmental impacts. Our future research will consider the quantitative analysis for the reaction products (bayerite, gibbsite) in addition to XRF analyses to better evaluate the composition of the reaction products. In addition, heat dissipation, $\mathrm{pH}$ control, the quality of the hydrogen gas and the reacted components should be investigated.

\section{Acknowledgements \\ The authors would like to thank Abdirahman Elmi and Eng. Yosouf Saleh of the Qatar Shell Research and Technology Centre Analytical Lab for carrying out the chemical digestion of the raw material to obtain their elemental compositions. Also the authors would like to thank Hydro and Qatalum for supplying the materials.}

Authors' contributions

EE 50\%, AE 30\% and YA 20\%. All authors read and approved the final manuscript.

\section{Competing interests}

The authors declare that they have no competing interests.

\section{Publisher's note}

Springer Nature remains neutral with regard to jurisdictional claims in published maps and institutional affiliations.

Received: 25 June 2016 Accepted: 27 February 2017

Published online: 24 March 2017

\section{References}

1. I. A. Institute, Primary aluminium production, 20 August 2015. [Online]. Available: http://www.world-aluminium.org/statistics/primary-aluminiumproduction/. Accessed 6 Sept 2015.

2. Calder VG and Stark TD (2010) Solid, aluminum reactions and problems in municipal solid waste landfills. Pract Period Hazard Toxic Radioactive Waste Manage. ASCE, 15(1): 258-265

3. Kravchenko OV, Semenenko KN and Bulychev BM (2005) Activation of aluminium metal and its reaction with water. J Alloys Compd. 397(1-2):5862

4. Pasley RS (2003) The physical and chemical reclamation and recycling of elements from black aluminium furnace residues. PhD Thesis. Brunel University, London. http://bura.brunel.ac.uk/handle/2438/7272

5. International energy data and analysis, EIA, (2015) [Online]. Available: https:// www.eia.gov/beta/international/analysis_includes/countries_long/Qatar/ qatar.pdf

6. Kazim A (2003) Feasibility of hydrogen energy production through natural gas steam reformation process in UAE. NATO Sci Ser II 172:467-472

7. Chuan W, Zhuang H, Baolian Y (2005) Recent advances in hydrogen generation with chemical methods. Prog Chem 17(3):423-429 
8. Stark TD, Martin JW, Gerbasi GT, Thalhamer T, Gortner RE (2012) Aluminum waste reaction indicator in a municipal solid waste landfill. J Geotech Geoenviron 138(3):252-261

9. Martin JW, Stark TD, Thalhamer T, Gerbasi-Graf GT, Gortner RE (2013) Detection of aluminum waste reactions and waste fires. J Hazard Toxic Radioact Waste 17(3):164-174

10. Stockburger D, Stannard JH, Rao BML, Kobasz W and Tuck CD (1992) On-line hydrogen generation from aluminium in an alkaline solution. Electrochem Soc. pp. 92-95

11. Uehara K, Takeshita H, Kotaka H (2002) Hydrogen gas generation in the wet cutting of aluminium and its alloys. J Mater Process Technol 127:174-177

12. Shaytura NS, Laritchev MN, Laritcheva OO, Shkolnikov EL (2010) Study of texture of hydroxides formed by aluminum oxidation with liquid water at various activation techniques. Curr Appl Phys 10:66-68

13. Watanabe M (2010) Chemical reactions in cracks of aluminum crystals: generation of hydrogen from water. J Phys Chem Solids 71:1251-1258

14. Mahmoodi K, Alinejad B (2010) Enhancement of hydrogen generation rate in reaction of aluminium with water. Int J Hydrog Energy 35:5227-5232

15. Parker JJ and Baldi AL (2009) Compostion and process for the displacement of hydrogen from water under standard temperature and pressure conditions. USA Patent US 2009/0280054 A1

16. Macanas J, Soler L, Candela AM, Munoz M, Casado J (2011) Hydrogen generation by aluminium corrosion in aqueous alkaline solutions of inorganic promoters: The AlHidrox process. Energy 36:2493-2501

17. Soler L, Macanas J, Munoz M, Casado J (2007) Aluminium and alumunium alloys as sources of hydrogen for fuel cell applications. J Power Sources 169: 144-149

18. Soler L, Candela AM, Macanas J, Munoz M, Casado J (2009) In situ generation from hydrogen from water by aluminium corrosion in solutions of sodium aluminate. J Power Sources 192:21-26

19. Martinez SS, Sanchez LA, Gallegos AAA, Sebastian PJ (2007) Aluminium and aluminium alloys as sources of hydrogen for fuel cells applications. J Power Sources 32:3159-3162

20. Wu C, Zhang H (2005) Recent advances in hydrogen generation with chemical methods. Renew Sust Energ Rev 13(4):845-853

21. Hiraki T, Akiyama T (2009) Exergetic life cycle assessment of new waste aluminium treatment system with co-production of pressurized hydrogen and aluminium hydroxide. Int J Hydrog Energy 34:153-161

22. Wang HZ, Leung DYZ, Leung MKH, Ni M (2009) A review on hydrogen production using aluminium and aluminium alloys. Renew Sust Energ Rev 13:845-853

23. Olivares-Ramírez JM, Marroquin de Jesus A, Jimenez-Sandoval O, Pless RC (2012) Hydrogen generation by treatment of aluminium metal with aqueous solutions: procedures and uses. In: Dragica M (ed) Hydrogen energy — challenges and perspectives. InTech, Rijeka, pp 55-76

24. Elsarrag E (2008) Experimental study of using fuel cells in dwellings for energy saving lighting and other low power applications. Int J Hydrog Energy 33(16):4427-4432

25. Rodrguez JP Energy content of some combustibles (in MJ/kg), Hofstra University, (2013) [Online]. Available: http://people.hofstra.edu/geotrans/ eng/ch8en/conc8en/energycontent.html.

\section{Submit your manuscript to a SpringerOpen ${ }^{\circ}$ journal and benefit from:}

- Convenient online submission

- Rigorous peer review

- Immediate publication on acceptance

- Open access: articles freely available online

- High visibility within the field

- Retaining the copyright to your article 